\title{
Ciganos: breve definição e análise dos movimentos sociais e políticas públicas no Brasil até 2014
}

Télia Resende de Sousa Lima

\section{Resumo:}

Este trabalho tem como objetivo analisar concisamente os aspectos dos movimentos sociais e a formulação de políticas públicas direcionadas a povos ciganos no Brasil até janeiro de 20I4, principalmente ao grupo Calon, ao qual pertence parte expressiva dos ciganos nômades brasileiros, submetidos à discriminação e à exclusão social. Considerando a carência de dados e pesquisas antropológicas específicas sobre ciganos no Brasil, o trabalho inclui como introdução breve histórico e definição da etnia cigana, além de caracterizar e teorizar a respeito da acentuada discriminação e preconceito a que esses povos são comumente expostos. Este estudo foi sustentado através de pesquisa a dados literários e eletrônicos, audiência a palestra e entrevistas.

Palavras-chave: Giganos - Calon - Políticas Públicas - Movimentos Sociais - Discriminação 


\section{Introdução: características gerais e breve histórico do povo cigano (roma)}

Quem são os ciganos? Abnegados pela história e rotineiramente aviltados pelos meios de comunicação e sociedade, os ciganos são indivíduos que tentam encontrar refúgio do preconceito, estereótipos e exclusão a que são submetidos apenas por fazerem parte de uma cultura distinta. Procuram ser ouvidos pela sociedade e ampliar o conhecimento sobre quem são através da disseminação de sua cultura e história, desde sempre envolta em mistérios. No Brasil, caminham timidamente em direção às políticas de integração, que são praticamente inexistentes, mesmo após 439 anos de existência cigana no país.

Para uma definição específica de quem são os povos ciganos, primeiramente é relevante introduzir duas questões principais. Primeiro, que o termo "cigano" é demasiadamente genérico, tendo em vista que a etnia divide-se entre vários grupos e subgrupos, conforme veremos adiante. Segundo, é interessante mencionar que o termo "cigano" tem sido mundialmente pouco utilizado, aplicando-se em seu lugar os termos "rom" (singular), "roma" (plural) e "romani" (adjetivo). Segundo a cigana do grupo Calon Márcia Yáskara Guelpa, presidente da ONG Centro de Estudos e Resgate da Cultura Cigana (informação verbal), ${ }^{1}$ a etimologia da palavra "cigano" já possui uma conotação pesada, pois significa "pessoa que faz magia" ou "pessoa intocável", definições que tiveram início com as concepções formuladas pela Igreja católica, já no século XVI. A utilização do termo "roma", em detrimento de "cigano" ou outras referências, foi legitimada em I97I pelo Primeiro Congresso Mundial Romani, realizado em Londres, no Reino Unido. Neste mesmo congresso também foi definido que os roma teriam como bandeira duas faixas horizontais de tamanho igual, azul na parte superior, simbolizando o céu, e verde na parte inferior, simbolizando a terra, com o desenho de uma roda vermelha de carroça no meio, simbolizando o nomadismo. Além disso, os roma também possuem um hino internacional, nomeado "Gelem, Gelem" (Caminhei, Caminhei), cantado em língua romani. "Eu também tive mulher e filhos bonitos, mataram minha família, os soldados de uniforme preto", diz uma das traduções do hino, referindo-se ao holocausto nazista, que dizimou grande parte da etnia.

\footnotetext{
I Palestra realizada no Ato Solene ao Povo Cigano, do programa SOS Racismo, na Assembleia Legislativa do Estado de São Paulo, Auditório Paulo Kobayashi, São Paulo, SP, em 03 dez. 20I3, com participação de Márcia Yáskara Guelpa e Rodrigo Tadeu Fernandes dos Santos, entre outros. Todas as citações de Yáskara Guelpa e Fernandes dos Santos se referem a essa palestra.
} 
Os roma são uma etnia heterogênea. Conforme já enunciado, dividem- se entre vários grupos, e no Brasil os mais expressivos são os Rom, os Calon e os Sinti, falantes, respectivamente, além da língua do país de origem, do romani, do caló e do sintó. Não possuem uma religião específica, podendo variar na adoção de uma ou de outra. Há um nível de estranhamento entre os Rom e os Calon, os primeiros muitas vezes definidos como "os verdadeiros ciganos", o que é bastante contestado. Sobre a prática do nomadismo, Nicolas Ramanush (2012) afirma que nunca se tratou de uma questão de costumes ou de escolha, mas sim de um resultado das inúmeras perseguições a que os ciganos são submetidos. Segundo ainda Frans Moonen (2012, p. I2), a questão do nomadismo e do sedentarismo é também um fator gerador de discriminações internas, considerando que os ciganos sedentários observam o nomadismo como uma forma de "vida primitiva", e, por vezes, os nômades questionam a autenticidade da identidade cigana dos sedentários, por terem eles "abandonado as tradições". No Brasil, especificamente, o nomadismo é um atributo apenas do grupo Calon, por se sustentarem de comércio que necessita de mobilidade para obtenção de novos clientes, e também por não encontrarem políticas de integração por parte do governo (RAMANUSH 20I2).

Pelo exposto e por diversas outras caracterizações, é possível constatar as intrínsecas dessemelhanças existentes entre os povos ciganos, sobre os quais afirmou o sociólogo Thomas Acton (I974, p. 55):

[Os ciganos] são um povo extremamente desunido e mal definido, possuindo uma continuidade, em vez de uma comunidade, de cultura. Indivíduos que compartilham a ascendência e a reputação de "cigano" podem ter quase nada em comum no seu modo de viver, na cultura visível ou na língua. Os ciganos provavelmente nunca foram um povo unido.

Considerando, então, as diversas vertentes culturais romani, Frans Moonen (20I2, p. I5) ofereceu como definição de quem é cigano: "Gigano é cada indivíduo que se considera membro de um grupo étnico que se autoidentifica como Rom, Sinti ou Calon, ou um de seus inúmeros subgrupos, e é por ele reconhecido como membro".

Acredita-se que devem existir entre 800 mil e I milhão de ciganos em todo o Brasil, segundo a Secretaria Especial de Políticas de Promoção da Igualdade Racial (SEPPIR). O censo do IBGE de 2010 encontrou acampamentos ciganos em 29I dos 5.565 municípios brasileiros, concentrados nas regiões Sul, Sudeste, Nordeste e Centro-Oeste. No entanto, esses dados são duramente contestados, e acredita-se que a real quantidade seja efetivamente 
Ciganos: breve definição e análise dos movimentos sociais e políticas públicas no Brasil até 2014

bem maior. O próprio governo reconhece a falta de dados sobre os povos ciganos, o que dificulta a criação de políticas públicas. A inclusão da etnia cigana no censo do IBGE e o mapeamento concreto dos acampamentos calon estão entre as reivindicações de vários movimentos sociais. Um dado interessante é que, mesmo o Brasil já tendo sido governado por um presidente de descendência cigana, Juscelino Kubitschek, medidas simples como essas não foram, até hoje, efetivadas.

Relativo à origem do povo cigano persistem muitos mitos, configurando-se a realidade como um mistério até os dias de hoje. Geralmente, acredita-se que são oriundos da Índia, devido a estudos que comprovaram diversas semelhanças entre a língua romani e o sânscrito, língua indiana. Importante se faz mencionar que as características culturais indianas adotadas por alguns ciganos, principalmente no que se refere ao vestuário e danças, são posteriores e se devem mesmo a essa descoberta. Nicolas Ramanush (2OII), autor de Cultura cigana, nossa história por nós, conta-nos que, entre os anos I300 e I400 os ciganos deixaram a Índia, dirigindo-se a Pérsia, Ásia Central, Bizâncio e países da Europa, onde foram identificados pela Igreja católica como feiticeiros, uma das origens dos estereótipos que até hoje se referenciam aos roma, conjuntamente à fama de ladrões, vigaristas etc. Após isso, na Espanha, foram passíveis de pena de morte, proibidos de utilizar vestuário e língua própria, a qual foi acusada de destinar-se a disfarçar a prática de crimes, dentre outras inúmeras perseguições. Assim, a diáspora cigana iniciou-se já a partir do século XIV, na Europa. A etnia foi escravizada por diversos lugares por onde passou, principalmente pelo fato de diversos ciganos serem ótimos metalúrgicos e fabricantes de armas, que eram usadas nas guerras, nas quais também cozinhavam e cuidavam dos feridos. Tendo sido proibidos de adentrar o Reino Português em I525, começaram a ser deportados para as colônias portuguesas Angola e Brasil. O primeiro registro de presença cigana no Brasil é datado de I574.

\section{Ciganos: gênese, expansão e efeitos da discriminação}

O que podemos observar na prática é que a diáspora do povo cigano, originada pela discriminação, teve como resultado a intensificação dela mesma. Os povos ciganos, segundo dados de 2013 da Anistia Internacional, são os mais discriminados da Europa, e é possível deduzir que o sejam até do planeta. Como em um círculo vicioso, os efeitos da exclusão social no Brasil direcionada aos Calon nômades, dentre eles a não frequência à escola, o desemprego e a pobreza, acabam por intensificar o preconceito e até justificar os estereó- 
tipos negativos que circundam essa etnia, não obstante o desconhecimento cultural socialmente generalizado que, por si só, já gera estranhamento.

Os ciganos nômades são definidos como povos apátridas, e os efeitos dessa particularidade sempre foram seus maiores e mais graves problemas, considerando a dimensão do conceito de nação e soberania nacional, conjugado aos direitos do homem desde o século XVIII pela Revolução Francesa, e patenteado com a eclosão da Segunda Guerra Mundial, no século XX, quando esta gerou uma enorme massa de refugiados que vagavam sem destino, alento e cidadania pela Europa de Estados-nação, que representavam o domínio da lei. Esses povos sem pátria, dentre os quais estavam os ciganos, além de não serem regidos ou protegidos por lei nacional alguma, não poderiam também ser alcançados pelos direitos humanos, embrionários em seu caráter prático. Como nos descreve Hannah Arendt (I989, p. 320), era melhor ser criminoso do que apátrida:

A melhor forma de determinar se uma pessoa foi expulsa do âmbito da lei é perguntar se, para ela, seria melhor cometer um crime. [...] Pois o crime passa a ser, então, a melhor forma de recuperação de certa igualdade humana, mesmo que ela seja reconhecida como exceção à norma. O fato - importante - é que a lei prevê essa exceção. Como criminoso, mesmo um apátrida não será tratado pior do que outro criminoso, isto é, será tratado como qualquer outra pessoa nas mesmas condições. Só como transgressor da lei pode o apátrida ser protegido pela lei.

Esses povos sem Estado ficaram tão numerosos que acabaram por se tornar o "refugo da terra" (id. ibid.), ou seja, um problema a ser solucionado pelos países da Europa, o que constituiu o gérmen incentivador do que posteriormente veio a ser o Holocausto. Acredita-se que até 500 mil ciganos possam ter sido exterminados nos campos de concentração nazistas: "Nós somos idênticos aos judeus. Sofremos exatamente o mesmo que eles", afirma a cigana Márcia Yáskara Guelpa. Mesmo assim, os ciganos são comumente esquecidos de serem mencionados até mesmo na história do Holocausto. "Todos puderam falar. Menos os homossexuais e os ciganos", complementa.

A respeito da discriminação, Michael Hanchard (200I, p. I8) afirma que ela é inerente a todos os povos que foram sujeitos historicamente a uma diáspora, sobre os quais observou, no Brasil:

os povos sujeitos a uma diáspora tinham sido submetidos a uma forma peculiar de escravidão racial e, nas diferentes nações onde residiam, pertenciam sempre 
Ciganos: breve definição e análise dos movimentos sociais e políticas públicas no Brasil até 2014

a um grupo subalterno, mesmo quando independentes. Além disso, essa escravização fazia parte de um processo mais abrangente de dominação racial, que também tinha consequências culturais, epistemológicas e ideológicas.

A cigana Yáskara afirma, ainda, que nesse sentido o Brasil é um "paraíso" se comparado com outros países do mundo. O calon Rodrigo Tadeu Fernandes dos Santos concorda: "A gente convive com o preconceito diariamente, mas no Brasil é diferente. Eu atribuo isso à miscigenação brasileira e à espiritualidade." Mas, mesmo no Brasil, famoso por ser um país onde não existe discriminação ou racismo, estereótipo que, além de inverídico, serviu para atrasar as discussões necessárias ao tema, os estereótipos que os ciganos receberam há séculos continuam corroborando a discriminação, e os Calons nômades ainda são proibidos de entrarem em lojas, não conseguem emprego, têm seus acampamentos invadidos e são comumente confundidos com ladrões e bandidos, mesmo na ausência de provas. Segundo Frans Moonen (2012, p. I05):

Muitos ciganos não conseguem, ou não têm o preparo profissional necessário para exercer outras atividades. Bancos, indústrias, supermercados ou lojas não costumam contratar ciganos. E assim a população cigana vai empobrecendo, sendo sempre mais empurrada para as favelas suburbanas, onde vivem miseravelmente, junto com não ciganos que vivem nas mesmas condições subumanas. E qualquer indivíduo que for obrigado a viver nestas condições - seja ele cigano ou não cigano - mais cedo ou mais tarde termina apelando para meios não convencionais e alternativos (isto é: criminosos) para sobreviver e garantir o sustento e a sobrevivência de sua família.

Assim, a prática delituosa constitui-se como um resultado, embora não generalizado, da exclusão a que os ciganos nômades e outras minorias são sujeitadas. Mais uma vez, um dos resultados da discriminação - a exclusão - apenas compele muitos ciganos e não ciganos a ela submetidos para a utilização de meios que geram a intensificação da mesma, e que podem ser utilizados como justificação do preconceito, tornando a questão da inclusão do povo cigano realmente complexa. Diante desse cenário, Yáskara afirma (informação verbal, ver n. I) que hoje no Brasil os inimigos dos ciganos são os prefeitos das cidades, de onde, quando não são proibidos de entrar, são expulsos, bem como que os ciganos consideram que sofrerem tanta discriminação por conta do desconhecimento, praticamente total, sobre sua cultura, desconhecimento este que induz ao preconceito: "Somos vitimados pela ignorância", afirma a cigana. 
Em outros países do mundo, ciganos são assassinados, deportados, as mulheres são esterilizadas, e outras atrocidades são cometidas, o que justifica o porquê de essa minoria étnica ser considerada uma das mais perseguidas e discriminadas do mundo.

\section{Organização política dos ciganos}

Os ciganos enfrentam reais dificuldades no que se refere à organização política. Segundo Frans Moonen (2OI2, pp. I26-27), é a desunião característica dos roma que explica a grande dificuldade de criar ONGs ou uma instituição internacional que os represente. A esse respeito, Moonen identifica os problemas gerais como os seguintes: a) Fraca identidade cigana; b) Problema da autoidentificação; c) Grande dispersão geográfica; d) Língua e comunicação; e) Rivalidade e competição; f) Liderança e organização; e g) Inexistência de programas.

Trabalhando esses tópicos, podemos melhor descrever os fatores impeditivos de uma organização política cigana efetiva como sendo, dentre outros, a heterogeneidade e a característica desunião étnica, considerando que existem inúmeros grupos de ciganos e alguns não reconhecem a identidade cigana do outro; o nomadismo, a distância e a falta de mapeamento dos acampamentos ciganos, que impedem a comunicação entre os diversos roma; a inexistência de uma língua internacional para que os grupos ciganos espalhados pelo mundo se comuniquem; e a dificuldade em criar um programa que abranja as necessidades de todos os grupos, por conta de suas particularidades e da falta de estudos aprofundados para conduzir as políticas públicas. Mais um empecilho é a necessidade de recursos financeiros para criar e manter uma organização política, tendo em vista que, como parte dos ciganos - a que mais necessita de políticas públicas específicas - não é abastada financeiramente, o investimento precisa ser conseguido através de financiadores externos, o que também é passível de originar outros conflitos, como corrupção, alienação do movimento etc.

Analisando os fatores impeditivos enumerados por Moonen e conforme exposto anteriormente, verificamos que estes podem ser resumidos em apenas uma terminologia: ausência de identidade coletiva. A identidade coletiva, conforme indica o sociólogo Alberto Melucci (I988, p. 342), constitui-se como uma "definição interativa e compartilhada produzida por numerosos indivíduos e relativa às orientações da ação e ao campo de oportunidades e constrangimentos no qual a ação acontece”. Ela é indispensável para a gênese de um movimento social e é construída pelos indivíduos que, "à medida que 
Ciganos: breve definição e análise dos movimentos sociais e políticas públicas no Brasil até 2014

se comunicam, produzem e negociam significados, avaliam e reconhecem o que têm em comum, tomam decisões" (ALONSO 2009, p. I7).

A identidade coletiva tanto é ausente nas organizações políticas ciganas que, dentre as 2I associações representativas de ciganos existentes no Brasil até 20I2, a maioria é composta por um grupo familiar, comumente pequeno, do que por uma união de ciganos de abrangência, no mínimo, regional. Além disso, são majoritariamente direcionadas à disseminação e conservação do patrimônio cultural, e não à militância de caráter econômico, social e/ou político, o que, aliás, não é uma particularidade dos movimentos ciganos.

\section{Políticas públicas para ciganos}

Analisando as reivindicações apresentadas pelos grupos de trabalho (GTs) ciganos convocados pelo governo federal a partir da gestão do presidente Lula para seus programas de inclusão de minorias e o seu resultado prático, o Guia de políticas públicas para povos ciganos, da Secretaria de Políticas de Promoção da Igualdade Racial (SEPPIR), lançado pelo governo federal em maio de 20I3, é possível detectar que a única política específica para ciganos que alcançou caráter prático é relacionada a cultura, muito embora a introdução ao guia relate como principais demandas "educação, saúde, registro civil, segurança, direitos humanos, transferência de renda e inclusão produtiva". As demais políticas públicas que constam no guia não são específicas a povos ciganos, mas programas direcionados a populações de baixa renda em geral, como Bolsa Família, Minha Casa, Minha Vida, Luz para Todos etc. O programa específico que já se encontra em prática denomina-se Prêmio Culturas Ciganas, e consiste em um concurso cultural que teve sua primeira edição em 2007 e busca premiar indivíduos ou instituições que elaborem o melhor trabalho que "contribua ao fortalecimento das expressões culturais ciganas". Há também o programa Pontos de Cultura, destinado a pessoas jurídicas de direito privado sem fins lucrativos que se interessem em promover convênios com o governo para fomento e conformação de pontos de cultura em seus territórios.

A SEPPIR, através do Guia de políticas públicas para povos ciganos, procura incentivar os ciganos carentes a registrarem seus filhos e a providenciarem sua documentação civil, o que se explica pelo fato de que, devido a grande parte dos ciganos não possuírem registro de nascimento ou documentos de registro civil, tais como RG e CPF, por conta do nomadismo e da "recusa sistemática desse grupo étnico a uma base territorial" (MELLO; VEIGA 20I2), os mesmos são excluídos do voto, do atendimento em hospitais, de matricular-se em 
escolas e de conseguir um emprego assalariado, o que, ressalte-se, também é dificultado pela discriminação. Um dos efeitos práticos dessa ausência, corroborado pela indiferença na realização de um mapeamento dos acampamentos ciganos no Brasil, é a impossibilidade de identificação dessas pessoas pelo governo. Outro fator a ser mencionado é que, mesmo para a obtenção dos benefícios mencionados pela SEPPIR para inclusão das populações de baixa renda, que constam como políticas públicas para ciganos, é necessário possuir um endereço fixo, o que contrasta com o nomadismo dos indivíduos ciganos aos quais interessam essas políticas. Projetos como a confeç̧ão de um Cartão Educação e Cartão Saúde, para que povos itinerantes possam ser matriculados em escolas e atendidos em hospitais, sem a exigência de endereço, têm sido muito discutidos, mas sem notícias de que tenham auferido resultado prático.

No ano de 2005, quando foi realizada a I ${ }^{\underline{a}}$ Conferência Nacional de Promoção da Igualdade Racial (Iaㅡ CONAPIR), em Brasília, foi realizada uma Audiência Cigana, duas semanas antes do evento, que ocorreu em junho, para formular propostas direcionadas ao encontro, o que rendeu 4I formulações, e a I ${ }^{a}$ CONAPIR aprovou I9. Posteriormente, em 2006, foi instituído oficialmente o Dia Nacional do Cigano, pelo então presidente Lula, a ser comemorado no dia 24 de maio de cada ano.

A 2 ${ }^{a}$ Conferência Nacional de Promoção da Igualdade Racial (2 ${ }^{a} \mathrm{CO}-$ NAPIR) foi realizada em Brasília, em junho de 2009, e foi marcada por desentendimento entre as organizações ciganas, o que prejudicou não só a apresentação das propostas de interesse da etnia, como o comparecimento de representantes de ONGs, por terem a autenticidade de sua identidade cigana questionada pela representante encaminhada ao evento, Mirian Stanescon. Tal conflito teve como resultado o veto a diversas propostas e a abertura de uma representação, na qual diversos ciganos alegaram que não se consideram representados por Stanescon.

Como é possível concluir, raros são os resultados práticos das poucas propostas que foram aprovadas relativas a políticas públicas direcionadas a ciganos, nos programas de inclusão de minorias recentemente empreendidos pelo governo federal. O desenvolvimento dos grupos de trabalho e as CONAPIRs demonstraram empiricamente a heterogeneidade dos grupos ciganos e o impacto da falta de informação sobre tais povos no Brasil, que se afirmaram como os maiores empecilhos para a inclusão política e social dos roma. A respeito da carência de informações, começou a ser discutida em 2013 a criação da disciplina ciganologia pelo departamento de História da Universidade de São Paulo.

Diante de todo o exposto, concluímos pela inexistência prática, até 20I3, de políticas públicas direcionadas especificamente a ciganos no Brasil. 
Ciganos: breve definição e análise dos movimentos sociais e políticas públicas no Brasil até 2014

\section{v. Considerações finais}

Tornou-se evidente a conclusão de que a promoção de medidas direcionadas a incluir a etnia cigana à sociedade encontra-se no começo, e de forma semelhante encontram-se os seus movimentos sociais, no tocante à organização e busca por medidas de inclusão socioeconômica. De fato, a discussão sobre discriminação e inclusão de minorias étnicas no Brasil é bastante recente, e isso se deve, principalmente, à difusa falsa concepção de que não existe discriminação, por tratar-se de país democrático onde se presencia a maior miscigenação de raças do mundo, estereótipo que persiste tão inveterado, que é difícil até hoje de ser eliminado. Para contrariar essa concepção basta observar que a raça, como termo abrangente, possui em si mesma e inclusive em nosso país um significado social e, segundo Michael Hanchard (200I, p. 7), paradoxalmente é a própria hegemonia racial que justifica tal conceito: "a hegemonia racial no Brasil contribuiu para estruturar a desigualdade racial, negar sua existência dentro da complexa ideologia da democracia racial e criar as precondições de sua perpetuação”.

Foi possível verificar a proeminência do caráter cultural das organizações sociais ciganas, bem como que as únicas políticas públicas específicas efetivamente aplicadas, se assim podem ser chamadas, referem-se a uma cerimônia de premiação para trabalhos de resgate cultural e visam parcerias com os governos para criação de pontos de cultura nos territórios das cidades. Algumas propostas de inclusão social foram discutidas nas CONAPIRs, mas não se tornaram políticas reais. O fato de que os ciganos nômades não votam também pode ser indicado como um fator gerador de desinteresse por parte do governo em melhorar a qualidade de vida dessas minorias. O minimalismo existente nas organizações sociais ciganas, no que se refere à reivindicação de políticas de inclusão social e econômica, pode ser explicado pelo fato de que geralmente os ciganos que possuem orçamento suficiente para inaugurar uma ONG ou outros tipos de agremiações políticas não necessitam de tais políticas redistributivas, pois, apesar de integrantes de uma cultura discriminada, não acumulam a discriminação por classe social, daí centralizarem seu empenho no reconhecimento cultural. Tendo em vista que o desconhecimento, praticamente total, sobre quem são os ciganos, ainda é o pilar principal que sustenta o preconceito, e considerando também o caráter embrionário da participação política dessa etnia, tudo indica a exatidão das palavras da Calon Márcia Yáskara Guelpa: "a cultura ainda é o melhor caminho" (ver n. I).

Conforme sugere Antonio Gramsci (I9I6), a cultura é uma apropriação da própria personalidade, e o homem, como construção histórica que é, 
necessita antes de autoconhecimento para ser capaz de iniciar uma luta política. O autoconhecimento só é possível se existir também conhecimento sobre o "outro". Portanto, é possível concluir que uma sociedade que desconhece as diversas culturas que dela fazem parte é uma sociedade que não possui conhecimento verdadeiro sobre si própria, e daí não obterá sucesso também em seus assuntos políticos. Gramsci assim definiu a importância da cultura, em sentido abrangente, para a política:

A cultura é algo bem diverso. É organização, disciplina do próprio eu interior, apropriação da própria personalidade, conquista de consciência superior: e é graças a isso que alguém consegue compreender seu próprio valor histórico, sua própria função na vida, seus próprios direitos e seus próprios deveres. [...] toda revolução foi precedida por um intenso e continuado trabalho de crítica, de penetração cultural, de impregnação de ideias em agregados de homens que eram inicialmente refratários e que só pensavam em resolver por si mesmos, dia a dia, hora a hora, seus próprios problemas econômicos e políticos, sem vínculos de solidariedade com os que se encontravam na mesma situação (GRAMSGI 29 jan. I9I6).

Os movimentos sociais ciganos encontram-se em um momento propício para o desenvolvimento, tendo em vista a importância e popularidade que permeia a discussão sobre os direitos humanos atualmente, sobretudo após os atentados terroristas de 200I, nos Estados Unidos. Como um exemplo a nível internacional, está em vigor a Decade OfRoma Inclusion (Década de Inclusão dos Roma), que iniciou-se em 2005 e pretende ser uma década de práticas de medidas para a inclusão econômica e social dos povos ciganos, aderida por doze países europeus: Albânia, Bósnia-Herzegovina, Bulgária, Croácia, República Tcheca, Hungria, Macedônia, Montenegro, Romênia, Sérvia, Eslováquia e Espanha.

Os movimentos sociais ciganos, apesar de diferenciados por tratarem de uma cultura quase totalmente desconhecida no Brasil, o que é um paradoxo se considerarmos que ela existe no país há, no mínimo, 439 anos, e também de se localizarem no início da obtenção de voz ativa no âmbito político nacional, possuem similaridades com outros movimentos. O seu caráter comum de resgate cultural e sua formação constituída de pequenos grupos, geralmente desunidos, não definem somente a si, mas correspondem a uma tendência geral dos novos movimentos sociais, constituídos por "antes grupos ou minorias do que grandes coletivos", com "demandas simbólicas, girando em torno do reconhecimento de identidades ou de estilos de vida.", e que "não se dirigiriam prioritariamente ao Estado, mas à sociedade civil, almejando mudanças culturais no longo prazo" (ALONSO 2009, p. I9). Os teóricos dos novos 
Ciganos: breve definição e análise dos movimentos sociais e políticas públicas no Brasil até 2014

movimentos sociais (Alain Touraine, Jürgen Habermas, Alberto Melucci etc.) detectaram a moderna tendência dos movimentos a incorporarem a si uma ênfase cultural. A diferença seria que, em movimentos como o dos negros e das mulheres, essa seria uma tendência posterior à centralidade da pauta de inclusão social, igualdade e redistribuição econômica, enquanto que para o movimento cigano, a ênfase cultural se constituiria como o começo. Essa tendência a buscar reconhecimento, predominantemente à inclusão, seria provocada pelo advento do neoliberalismo político-econômico e seu individualismo inerente (FRASER 2007).

Para o povo cigano, que diferentemente das demais minorias praticamente nenhuma realização efetiva obteve para sua inclusão, é necessário persistir em ponderar sobre políticas públicas de ordem social e econômica, para as quais a cultura apresenta-se como uma porta de entrada conveniente. Reivindicações de ordem educacional e de saúde, mais do que necessárias, constituem-se como emergenciais, assim como o registro civil preliminar à satisfação dessas necessidades. Como um passo inicial para a efetivação desses objetivos está o suprimento de informações e dados através da promoção de pesquisas necessárias para que o país conheça quem são os ciganos brasileiros, onde estão e, finalmente, do que precisam. A inclusão da categoria "cigano" no formulário do censo do IBGE seria uma medida simples e iniciatória a fim de se obter dados demográficos sobre essa população, tendo em vista que os hoje existentes são ainda questionáveis. $O$ conhecimento é a primeira providência que necessita ser tomada. "Nós estamos nas mãos dos acadêmicos", afirmou a cigana Márcia Yáskara Guelpa (ver n. I).

\section{Referências bibliográficas}

AGTON, Thomas. Gypsy Politics and Social Change. Londres: Routledge \& Kegan Paul, I974.

ALONSO, Angela. As teorias dos movimentos sociais: um balanço do debate. Lua Nova, São Paulo, n. 76, 2009, pp. 49-86.

ARENDT, Hannah. Origens do totalitarismo. Trad. de Roberto Raposo. São Paulo: Companhia das Letras, I989.

FRASER, Nancy. Mapeando a imaginação feminista: da redistribuição ao reconhecimento e à representação. Estudos Feministas, v. I5, n. 2, 2007, pp. 29I-307.

GRAMSCI, Antonio. Socialismo e cultura. Il Grido del Popolo, 29 jan. I9I6.

HANGHARD, Michael George. Orfeu e o poder: movimento negro no Rio e São Paulo (I945-I988). Trad. de Vera Ribeiro. Rio de Janeiro: Eduerj, 200 I. 
MELLO, Marco Antonio da Silva; VEIGA, Felipe Berocan. Os ciganos e as políticas de reconhecimento: desafios contemporâneos. Associação Brasileira de Antropologia, 2012.

MELUCGI, Alberto. The New Social Movements: a Theoretical Approach. Social Science Information, v. I9, n. 2, 1980.

MOONEN, Frans. Anticiganismo e políticas ciganas, na Europa e no Brasil - versão 2012. Disponível em: <http://pfdc.pgr.mpf.mp.br/atuacao-e-conteudos-de-apoio/ publicacoes/discriminacao/anticiganisno-e-politicas-ciganas-na-europa-e-no-brasil-frans-moonen-2012>. Acesso em 29 dez. 2013.

RAMANUSH, Nicolas. Cultura cigana, nossa história por nós - partes I e II. Embaixada Gigana do Brasil "Phralipen Romane", 20II. Disponível em: <http: www. embaixadacigana.com.br>. Acesso em 29 dez. 2013.

. (Presidente da Embaixada Gigana do Brasil "Phralipen Romane"). Entrevista [I9 dez. 20I3]. Entrevistadora: a autora. São Paulo, 2013.

SEPPIR: Secretaria de Políticas de Promoção da Igualdade Racial (BR). Guia de políticas públicas para povos ciganos. Brasília: SEPPIR, maio de 20I3. Disponível em: <http://www.seppir.gov.br/.arquivos/guia-de-politicas-publicas-para-povos-ciganos>. Acesso em: $29 \mathrm{dez} .2013$.

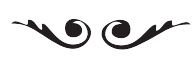

Télia Resende de Sousa Lima - Graduanda em Giências Sociais pela Universidade de São Paulo. trslima@hotmail.com 